\title{
Research on the Development of Smart Ship Maritime Education Based on Internet +
}

\author{
Ma Libo \\ Tianjin maritime college \\ Tianjin China
}

\begin{abstract}
The purpose of this paper is to study the impact of smart ships on navigation in the future. The research method is to analyze the current development of smart ships, analyze the problems facing maritime education, study the requirements of new navigation technologies and new knowledge, development. The result of the study is to propose the need of smart ships for navigation education, including knowledge-update pedagogy, pedagogical updates, college support and state support. Innovation is the combination of maritime education long-term development plan, the development of marine education in the era of intelligent ship teaching.
\end{abstract}

Keywords-Smart Ship; Maritime Education; Teaching Innovation; Internet +

\section{INTRODUCTION}

Based on the Internet+ education, we should adapt to the education system development requirements of the Ministry of Education of "13th Five-Year Plan for Education Information" and build a networked, digitized, personalized and life-long education system. With the development of education Information, information technology entered the classroom with unprecedented speed. By changing the way of learning, in order to promote the development of students and adapt to the knowledge, abilities and accomplishments required in the information age, the new information-based teaching mode should be gradually explored to adapt to this new change and challenge. Smart ship is the research hotspot in the field of modern smart automation. Information $\mathrm{n}$ and intelligence are the development directions of the maritime military. The application of intelligence is a research hotspot in the maritime field. In the field of ship, the key technology of Chinese intelligent ships is to Preliminary Study [1]. In 2016, the Ministry of Industry and Information Technology formally approved the $\mathrm{R} \& \mathrm{D}$ project of smart vessels, which was organized by Shanghai Ship Research and Design Institute and more than 20 units including China Merchants Energy Transportation Co. Ltd., study in depth the technology system related to smart ships, a clear design of smart ship design, research and development related to smart functions, and the realization of real ship applications. The development of navigation requires sailing education to keep pace with the times and put forward new requirements on navigational knowledge and skills, teachers' teaching and college and state support [2]. Internet + education lies in its more inclusiveness. It combines communications technology, computer technology, mobile technology, network technology in one, emphasizing the activities of online and offline together to create a new education for the design, development, utilization, management and evaluation of the form. The Internet + for teacher professional development, more teachers online growth channel reconstruction and reorganization, plus is in practice with the Internet and other new technologies combined teaching innovation.

\section{SMART SHIP DEVELOPMENT}

In order to comply with IMO's development trend of Enavigation and the urgent need of ship's intelligent technology application in the shipping market. On the basis of modern Internet technology featuring data technology (DT), a unified network platform and information platform is set up to carry out the development of common technologies, key equipment and systems for smart ships, complete with comprehensive energy efficiency management of ships, equipment operation and maintenance, cargo condition monitoring, autonomous driving assistance decision-making and ship-shore integrated communications management functions. According to the requirements of international ship monitoring, reporting and verification rules.The topic of Development of Ship-Assisted Autonomous Driving System is the subject of Special Research and Development of Smart Ship. The main content of this project is based on the integrated navigation technology and the intelligent platform of intelligent ships, intelligent information platform and related intelligent functions, the company developed a ship-assisted automatic piloting system with the functions of perception, decision-making and execution by carrying out researches on the comprehensive perception of the marine environment and navigation situation, the comprehensive optimization of the shipping route and speed, and collision avoidance assistance decision-making to realize the realization of ship speed and navigation Automatic control of traces, to achieve automatic collision avoidance driving in open waters and to complete demonstration of real ships. Intelligence is the main direction of the development of the ship and also the key development area of Made in China 2025 [3], which is the breakthrough of the special core technology of smart ship. The E-navigation strategy advocated by the international maritime organization (IMO) is also based on the intelligent ship. To develop the ship-assisted automatic piloting system to enhance the overall design, construction, operation, maintenance and management capabilities of China's shipbuilding industry in autonomous driving so as to enhance the safety and economy of ship shipping in an all-round way and ensure the realization and enhancement of China's smart vessels The comprehensive competitiveness of China's shipbuilding industry in designing, supporting and building and 
the autonomous controllable ability of core products are important channels for China's shipbuilding industry to adjust its industrial structure, The comprehensive competitiveness of China's shipbuilding industry in designing, supporting and building and the autonomous controllable ability of core products are important channels for China's shipbuilding industry to adjust its industrial structure, the subject of the shipassisted automatic piloting system, according to the marine meteorology, the ship's own design and dynamic characteristics and voyage tasks automatically planning a reasonable route and speed, and to achieve the ocean on the automatic driving, and even open water automatic collision avoidance, can be extremely greatly reduce the labor intensity of the crew to improve navigation safety, while effectively reducing the operating costs of ships, in the future will inevitably become the standard configuration of smart ships. Ship equipment monitoring and management, ship dynamic trajectory, video surveillance, video conferencing, file and database management, intelligent selection of communication channels .Online monitoring of ship navigational condition, energy efficiency and energy-consuming condition, automatic collection of data and obtaining meteorological and environmental data; Risk assessment is to be carried out to the system. During system design and analysis, relevant failure conditions and system response to such failure conditions are to be determined. The interaction between faults is to be eliminated or restricted by means of design of software and hardware of relevant equipment while fault detection and tolerance are to be provided. In addition to the software testing within the normal range, the testing in abnormal range is also to be carried.

\section{MARITIME EdUCATION FACES PROBLEMS AND COUNTERMEASURES}

When a ship sails or anchors at sea, its security status will inevitably be affected by many factors such as hydrological weather conditions, sea conditions, navigable densities including the mechanical conditions of ships. And all the factors of the outside world and our drivers and company managers are closely related. All are inextricably linked with factors such as sense of responsibility, skill qualifications, physical and mental condition, and resilience of our people. They are inextricably linked with each other and their skills and experience are not inherent. Every navigational "man" can not get to the ground in one step, and before going to work, he has to master the necessary theoretical knowledge of navigational theory, ship art[5] (ship structure, mechanical principle, ship steering, and steering effect) Mastery is crucial.

\section{A. Knowledge update}

Knowledge of three major aspects of a smart ship knowledge includes the knowledge of automatic navigation on board, knowledge of maritime communications at ship's shore and shore-based support knowledge of shipping companies, as shown in Figure1.

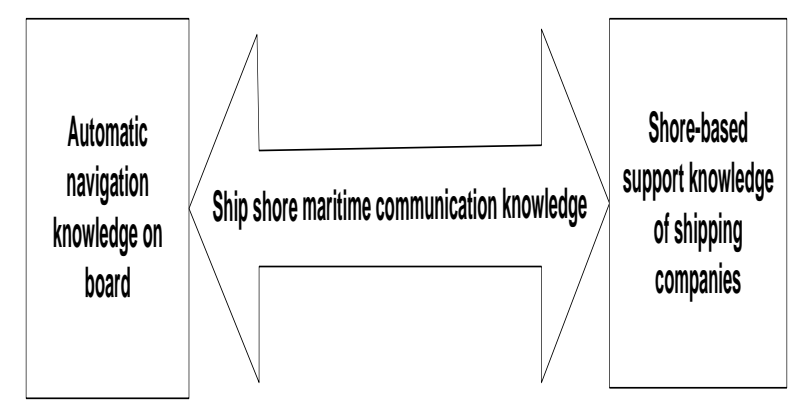

Fig. 1. Smart ships need three aspects of knowledge

The knowledge of automatic navigation on ships includes the fusion of multi-scale information obtained from the dynamic targets obtained by visible high-definition cameras and infrared thermal imagers to ensure the navigation ability of intelligent ships. The theory and method of target recognition based on machine vision are studied, Such as the technology of sea surface infrared and visible light image fusion technology, the sea small target detection technology, the sea surface target pattern recognition and other key technologies; integrated highprecision electronic chart information and shore-based meteorology, sea state forecast information, access to intelligent ship navigation in front of the static target Information and conditions of navigation information, to achieve intelligent shipping around the situation of the full seamless perception. The internal environment information includes equipment information such as the working status of the bridge and cabin equipment, and cargo status information such as the temperature and humidity of the cargo hold and the cargo. In order to comprehensively monitor the working status of the equipment, sensors such as temperature sensors, vibration sensors and noise collecting equipment should be added inside or outside the equipment, and temperature, vibration and noise analysis techniques should be used to comprehensively analyze the working status of the equipment, faults reasons and remaining life. Cargo and cargo monitoring, should measure the temperature, humidity, water content, concentration, location, shape and other parameters, and the parameters sent to the intelligent decision-making center in time for intelligent decision-making center at any time to grasp the status of cargo and cargo . The technologies involved in cargo hold and cargo monitoring include: wireless sensor network technology, radio frequency identification technology, ultrasonic technology, indoor positioning technology and so on [6].

Shipwreck maritime communications include the need to transmit large amounts of sensor information and equipment status information between ship and shore, as well as radar images, sea video, etc., the traffic is large, the data needs to be compressed intelligently and then transmitted to save the purpose of the fee. In different weather conditions to ensure smooth communication between the ship shore, intelligent ships equipped with different types of communication systems, the main maritime satellite system, a small microwave terminal, 
very small microwave terminal, iridium, the public mobile communications, such as compass . Intelligent choice of data in different scenarios to send ways to improve the overall performance of maritime communications systems, and reduce delays and costs, this technology is called intelligent routing technology. When only one communication system is available, priority will be given to sending high priority data. For example, in the case of ship-based remote collision avoidance, priority messages will be sent and meteorological messages will be sent. When multiple communication systems are available, factors such as data priority, delay of communication system and cost are taken into account. For example, when navigating nearsighted and receiving chart correction, priority should be given to public mobile communication. At Navigational Data [6], communications technologies such as the da-ta exchange system are mature and can be used as part of a maritime communications system to further enhance the reliability of ship-to-shore communications.

For a wide range of information, tropical cyclone pathways on the route, storm information, tidal waves and berths at the port of destination, shore-based support systems are required. Smart ships rely more on shore-based support and require shore-based support systems to provide a wide range of rich, high-precision information. To harmonize the collection, integration, exchange, display and analysis of maritime information by means of electronic means on ships and shorelines so as to enhance the navigation of ships from dock to dock and related services so as to achieve the purpose of maritime safety, security and marine environmental protection. Therefore, e Ship-to-sea information exchange, integration and integration highlighted by the "Navigation strategy laid the foundation for the development of smart ships. Smart ships also promoted the implementation and application of eNavigation.

\section{B. Teaching updates}

Traditional teaching methods can not fully meet the requirements of students and smart ships for high-quality personnel, teaching methods should use modern network technology, information technology teaching. That is to say, all aspects of navigation include digitization of teaching information technology teaching. modes, information technology, teaching evaluation, maritime environment, teachers and students' concepts, teacher and teaching organizations, teaching content of theory and practice, etc. So as to improve navigation teaching quality and students. The efficiency of learning. Teacher classification management and classification of evaluation methods, according to the characteristics of maritime professional salaried professional teachers or professional titles or job evaluation, hiring, assessment, promotion, rewards and punishments. Strengthen the construction of double-qualified [7] professional teachers.

Engaged in professional teaching of teachers on board, to ensure that the certificate of competency of teachers continued to be effective [8]. Engage sailing practical experience, good overall quality of the captain, chief engineer as a full-time, part-time teacher. Organize the development of sailing professional teacher training program, focusing on solving the navigation class professional certificate of competency certificate holders and shortage of teachers.

\section{College Support}

The college should increase investment in maritime education, including the introduction of academic leaders, new knowledge and driverless aspects of personnel, to enhance teachers' in-service learning, improve their knowledge level and suitable for driverless practical ability. Strengthen scientific research support, establish a reasonable system, teachers' enthusiasm and initiative to study new knowledge. Maritime institutions should further increase investment in sailing education, and actually perform their responsibility of running schools to ensure that investment in sailing education will steadily increase with the increase of investment in education in the country, so as to improve teaching conditions of sailing majors. The newly-added educational funds should be put into navigation majors professionally. According to relevant standards, practical teaching equipment and facilities shall be provided in sufficient quantity, variety and adaptation to the development of new maritime technologies so as to ensure effective practice teaching. Strengthen the construction of practical teaching conditions. Education administrative departments and transportation departments jointly build a number of maritime specialty points, with emphasis on strengthening the education and training bases in and out of schools. Improve relevant policies and measures to encourage and promote the shipping companies to increase the ship internship space, to receive students embark on the internship. Actively promote the formation of national internship fleet.

\section{National policy support}

The driver must also have some sailing experience. The requirements of the STCW convention for crew certification require a certain degree of maritime service qualification. Engineers need to have some experience and maritime service qualifications, the need for the state to provide internships in the school during the period, or through the purchase of jobs to enterprises so that students can have the STCW convention requirements [8], mainly through the students after graduation, at employer graduation to practice practical education. In order to standardize the maritime education in our country and in accordance with certain procedures, the competent national authority aiming at cultivating the merchant seamen in line with the relevant international conventions and domestic laws, the enforcement of the law of maritime education.

\section{CONCLUSION}

To study how the navigation colleges and universities face the arrival of the smart ship era and how to adjust the personnel training strategy to meet the challenges and opportunities brought by smart ships, Maritime education needs to redefine the goal of positioning and training, readjust the structure and level of education, update the teaching content in time, vigorously improve the teaching conditions, strive to improve the quality of teachers and improve the management system as soon as possible. 


\section{ACKNOWLEDGMENT}

This work was financially supported by 2016 higher vocational and technical education research association of Tianjin, research on the effectiveness and evaluation of ship security consciousness and responsibility course based on cloud computing (Grant No. XVI130).

\section{REFERENCES}

[1] DAI Shu-Long, LIU Shu-Ping, SUN Jian, DU Lin-Hai, GONG YuGuang.Global Data Platform for International Maritime Education and Training Based on Information Sharing [J]. Maritime Education Research, 2017,34 (01): 15-19. (In Chinese)

[2] ZHAO Jian, ZHAO Lu, WANG Xin-jian.Comparative Analysis and Reference of Maritime Education Models in China and Other Countries [J]. Marine Education Research, 2017,34 (01): 41-45. (In Chinese)
[3] Wen Yuanquan, Liu Yu. Survey and Analysis of the Development of Maritime Education in China during the 12th Five-year Plan [J]. Marine Education Research,2016,33 (04): 5-14. (In Chinese)

[4] Ma Jianwen, Hu Bancai, Zhang Ao, Jin Han Sheng.Participation on the Development of Maritime Education under the Strategy of "One Belt and One Road" [J]. Tianjin Maritime, 2016, (01): 52-54. (In Chinese)

[5] ZOU Chun-ming, WEN Yuan-qiao.Reflections on the Development of Maritime Education in Research-oriented Universities [J]. Marine Education Research, 2016,33 (01): 1-5. (In Chinese)

[6] ZHANG Rong-xuan. Influential Factors and Educational Strategies on the Stability of Maritime Professional Thoughts [J]. Marine Education Research, 2017,34 (02): 107-109. (In Chinese)

[7] Wen Yuanquan.Strategic Reflection on the Training of New Engineering and Talents in Navigation [J]. Marine Education Research, 2017,34 (03): 10-14. (In Chinese)

[8] LI De-rong, LI Han-tao, GAO Hui.Analysis of the Development Mode of Domestic Internet Education [J]. Modern Vocational Education, 2017, (15): 14. (In Chinese) 